\section{Research Square}

Preprints are preliminary reports that have not undergone peer review.

They should not be considered conclusive, used to inform clinical practice, or referenced by the media as validated information.

\title{
Invasion-induced root-fungal disruptions alter plant water and nitrogen economies
}

Lalasia Bialic-Murphy ( $\square$ lalasia.murphy@gmail.com )

University of Tennessee at Knoxville https://orcid.org/0000-0001-6046-8316

Nicholas Smith

Texas Tech University https://orcid.org/0000-0001-7048-4387

\section{Priya Voothuluru}

University of Tennesse Knoxville

\section{Robert McElderry}

University Of Tennessee Knoxville

\section{Morgan Roche}

University Of Tennessee Knoxville

\section{Cassidy Steven}

University of Florida

\section{Stephanie Kivlin}

University of New Mexico

\section{Susan Kalisz}

University of Tennessee

\section{Article}

Keywords: Allelopathy, root-fungal symbionts, least cost theory, water use efficiency, nutrient use efficiency, plant invasion, mutualism disruption, soil microbial community, AM soil fungi, and plant traits

Posted Date: August 28th, 2020

DOI: https://doi.org/10.21203/rs.3.rs-49360/v1

License: (9) This work is licensed under a Creative Commons Attribution 4.0 International License.

Read Full License

Version of Record: A version of this preprint was published at Ecology Letters on March 23rd, 2021. See the published version at https://doi.org/10.1111/ele.13724. 
1 Invasion-induced root-fungal disruptions alter plant water and nitrogen economies.

3 Key words: Allelopathy, root-fungal symbionts, least cost theory, water use efficiency, nutrient

4 use efficiency, plant invasion, mutualism disruption, soil microbial community, AM soil fungi, 5 and plant traits.

\section{Abstract}

8 Despite widespread evidence that biological invasion influences the biotic and abiotic soil

9 environments, the extent to which each of these pathways underpins the effects of invasion on

10 native plant traits and performance is unknown. Leveraging a long-term (14-yr) manipulative

11 field experiment, we show that an allelochemical-producing invader, Alliaria petiolata, affects

12 native plants through biotic mechanisms, altering the soil fungal community composition, with

13 no apparent shifts in soil nutrient availability. These changes in belowground soil fungal

14 communities resulted in a high cost of resource uptake for native forest perennial herbs and a

15 shift in functional traits linked to their carbon and nutrient economies. Furthermore, we illustrate

16 that some species in the invaded community compensate for high nutrient costs by reducing

17 nutrient uptake and maintaining photosynthesis by expending more water. This demonstrates a

18 trade-off in trait investment that increases nutrient use efficiency as nutrient costs increase. Our

19 results show that invasion-induced disruptions in the soil fungal community belowground can

20 cascade to affect aboveground plant communities via shifts in physiological traits needed to

21 maintain plant water and nutrient economies. These complex above-belowground linkages

22 suggest that plant invasions should be evaluated at the system-level to fully understand and

23 predict their impact on native plants and communities. 


\section{$24 \quad$ Main text}

25 Invasive plants have strong negative impacts on population dynamics of native species,

26 community assemblages, and ecosystem processes ${ }^{1}$. Two hypotheses may explain the impacts of

27 invasive species on native ecosystems: (1) shifts in soil resource availability ${ }^{2,3}$ and (2) disruption

28 of belowground microbial-mediated resource provisioning ${ }^{4}$. Both pathways result in the same

29 physiological signature of resource limitation for native plants and are therefore difficult to

30 disentangle with physiological trait measurements alone. Moreover, while evidence supports

31 both invasion hypotheses individually, invasive species commonly modify abiotic soil resources

32 and disrupt biotic interactions simultaneously and the cascading effects of invasion belowground

33 are rarely linked to aboveground impacts ${ }^{5,6}$. Gaining new insight into the mechanisms

34 underlying successful plant invasion requires tracing invasion-induced changes in belowground

35 soil dynamics to shifts in native plant traits and performance.

37 Many invasive species increase the quantity and quality of leaf litter and rhizodeposition, leaving

38 long-lasting effects on abiotic soil resource availability and carbon, nitrogen, and water cycles ${ }^{2,7}$.

39 If invasive species increase nutrient concentrations, belowground microbial mutualisms with

40 native species may be disrupted (Figure $1 \mathrm{c})^{8}$. Other invasive species may have specialized roots

41 or high root density, making the invasive species superior to natives at capturing limited

42 resources ${ }^{9}$. If invaders are superior soil resource competitors, invasive species will deplete soil

43 resource availability to lower levels than can be tolerated by native species ${ }^{10}$, resulting in

44 physiological stress and reduced native plant performance (Figure 1b). 
46 While only recently investigated as a mechanism of invasion success, many of the world's most

47 successful invaders alter soil microbiome abundance and diversity and disrupt plant-microbial

48 interactions ${ }^{11,12}$. Invasion-induced changes in soil microbiomes are driven by specialized

49 microbial associations with non-native plant hosts ${ }^{13,14}$, altered plant diversity ${ }^{15}$, altered plant-soil

50 feedbacks ${ }^{16}$, and direct toxicity of soil microbes via the production of allelochemicals ${ }^{17}$. A shift

51 in soil microbiome abundance and diversity and the disruption of plant-microbial interactions

52 can have dramatic effects on soil resource provisioning to native plant partners ${ }^{18}$. Among the

53 most important plant-microbial symbionts for resource exchange is the association between

54 arbuscular mycorrhizal (AM) fungi (Glomeromycotina) that obligately live in plant roots of at

55 least $70 \%$ of land plant species ${ }^{19}$. The foundation of this symbiosis is a two-way exchange of

56 resources: AM fungi receive $20-40 \%$ of their host plant's carbon $(\mathrm{C})^{20}$, and in turn boost the

57 supply of soil resources (water, phosphorus $(\mathrm{P})$, and nitrogen $(\mathrm{N})$ ) to their host plant ${ }^{21-23}$. If the

58 mechanism driving reduced native plant performance following biological invasion is the

59 disruption of soil resource provisioning by microbial symbionts (mutualism disruption

60 hypothesis ${ }^{24}$ ), then biological invasion would induce physiological stress of resident plants with

61 no apparent change in soil resource availability (Figure 1c).

63 Invasion-induced reductions in the availability and provisioning of soil nutrients and water can

64 leave unique physiological signatures on native plants (Figure 2). In response to invasion-

65 induced resource limitations, native plants can change their morphological, physiological, and

66 internal anatomical traits to increase resource use efficiency of leaf tissues. For instance, in

67 response to reduced water availability plants tend to decrease their specific leaf area (SLA) ${ }^{25}$,

68 allowing for greater leaf-level photosynthetic water use efficiency (WUE) by reducing the 
69 surface area from which water is lost (Figure 2). However, SLA shows only a limited response to

70 soil nutrients ${ }^{26}$. Stomatal conductance also decreases with increasing water stress ${ }^{27-29}$, increasing

71 WUE, particularly if plants increase nutrient uptake to support photosynthesis under water

72 limitation ${ }^{30,31}$. However, this results in a decrease in photosynthetic nutrient use efficiency

73 (PNUE) under water limitation ${ }^{30}$. Conversely, reduced nutrient availability tends to increase

74 PNUE and decrease WUE ${ }^{30}$. This trade-off leads to the prediction that plants under water stress

75 would have higher nitrogen per leaf area $\left(\mathrm{N}_{\text {area }}\right)$ for a given rate of stomatal conductance $\left(\mathrm{g}_{\mathrm{s}}\right)$

76 relative to plants under low water stress (Figure 2). Alternatively, one would expect a decrease in

$77 \mathrm{~N}_{\text {area }}$ at a given $\mathrm{g}_{\mathrm{s}}$ with soil nutrient stress. This trade-off has been confirmed in global

78 observations ${ }^{32}$, but has not been examined in an invasion context. We expect the optimal

79 combination of photosynthetic traits to shift if invasive species alter the availability or

80 provisioning of one or more soil resources. In this scenario, native plants in the invaded

81 community that are best able to shift their morphological, anatomical, and physiological traits are

82 likely to be the least impacted by invasion.

84 While physiological responses may help to maintain per-leaf-area rates of photosynthesis, they

85 may only have limited benefit to whole-plant performance (i.e., biomass accumulation and

86 reproduction) if the soil resources necessary to build new tissues are severely limited (Figure 1e).

87 Indeed, biomass responses to soil resource availability are very strong ${ }^{33,34}$. This may cause a

88 negative feedback to invasion if invasion-induced reductions in resource availability limit

89 nutrient acquisition by suppressing root growth.

90 
91 Here, we explore the effects of an allelochemical-producing invader on belowground processes

92 and explicitly link these changes to shifts in native plant traits, resource use efficiencies, and

93 growth. Our primary objective was to distinguish between altered soil resource availability

94 (depletion or enhancement) versus plant-fungal mutualism disruption as pathways underpinning

95 invasion-induced shifts in native plant traits and performance (Figure 1). The invader we

96 investigated, Alliaria petiolata (Brassicaceae), is a biennial herb from Eurasia that produces

97 secondary compounds toxic to AM fungi ${ }^{35,36}$. This study leverages a 14-yr long manipulative

98 field experiment, in which Alliaria was weeded from one side of five paired plots and was left at

99 ambient densities on the other side of each plot. Our specific aims were to evaluate the extent to

100 which long-term removal of Alliaria leads to changes in (1) the availability of key limiting soil

101 resources (including nitrogen, phosphorous, soil moisture), (2) the soil AM fungal community

102 and abundance of AM fungi in native plant roots, (3) shifts in traits and resource use efficiencies

103 of native forest understory perennials, and (4) changes in whole-plant biomass accumulation.

105 To capture potential differences in abiotic soil properties and microbial communities, we 106 collected soil cores and root samples for a subset of native forest perennials within the Alliaria

107 ambient and weeded treatments. To trace the effects of altered belowground dynamics on native

108 plant traits and performance, we measured a suite of morphological and physiological traits and

109 recorded plant size annually for two consecutive years. To account for potential differences in

110 native plant traits due to variation in light availability, we also measured diffuse and direct beam

111 radiation in the forest understory. Our focal native plant species were Arisaema triphyllum,

112 Trillium erectum, and Maianthemum racemosum. These species were selected because they are 
113 widespread perennial herbs throughout eastern North American forests that form root-AM fungal 114 associations ${ }^{37}$.

116 If the focal native species follow the predictions of the mutualism disruption hypothesis, we 117 predict that the long-term removal of Alliaria would increase AM fungal root colonization and 118 alter the AM soil fungal composition. These changes in AM fungal associations would increase 119 soil resource provisioning to the native plant partners, detectable as a decrease in SLA and 120 increase in $\mathrm{N}_{\text {area }}$. We expect similar shifts if Alliaria directly lowers soil resource availability for

121 native plant species. At the whole-plant level, we expect higher native plant growth in the

122 Alliaria weeded treatment than the ambient treatment due to increased soil resource availability 123 or provisioning.

\section{Results}

126 Soil properties

127 We found that hyphal length of AM fungi (i.e., aseptate hyphae) in the organic soil layer was 128 lower in Alliaria weeded plots compared to ambient plots $(P=0.047$; Figure 3$)$. However, this 129 effect disappeared in bulk soils $(P=0.093)$. Regardless of whether the organic and mineral 130 layers were analyzed separately or as a weighted mean (bulk soils), no other soil properties 131 differed between the Alliaria treatments $(P>0.050$, Figure 3$)$.

\section{Soil AM fungal communities}

134 In the organic soil layer, AM fungal Shannon-Wiener diversity was significantly lower in the 135 weeded treatment than the ambient treatment $(P=0.039$; Figure $4 \mathrm{~b})$, but all other measures of 
136 AM fungal diversity did not vary between treatments $(P>0.050)$. Soil AM fungal community

137 composition in the organic layer also did not vary between Alliaria treatments $\left(R^{2}=0.074, P=\right.$

$138 \quad 0.377$; Figure 4a).

139

140 In the mineral soil, neither AM fungal Shannon-Wiener diversity $(P=0.778)$ nor Simpson index

$141(P=0.160)$ varied between the Alliaria treatments (Figure 4e, f). However, the soil AM fungal

142 community composition in the mineral layer differed between treatments $\left(R^{2}=0.168, P=0.023\right.$;

143 Figure 4d).

145 AM fungal root colonization

146 Colonization of native plant roots by arbuscules $(P<0.001$; Figure 5a) and aseptate hyphae $(P=$

1470.009 , Figure 5d) in Arisaema was higher in the Alliaria weeded treatment than the ambient

148 treatment. For Maianthemum, there was no difference between treatments in the root

149 colonization by arbuscules $(P=0.335$; Figure $5 b)$ or aseptate hyphae $(P=0.184$; Figure 5e).

150 Similarly, there was no difference between treatments in the root colonization by arbuscules $(P=$

1510.608 ; Figure 5c) and lower colonization by aseptate hyphae $(P=0.002$; Figure $5 f)$ in the

152 weeded treatment for Trillium.

153

154 Light availability and canopy openness

155 Overall, total diffuse and direct beam radiation did not vary between the Alliaria treatments $(P=$

156 0.717). These results indicate morphological and physiological trait differences between

157 treatments were not driven by variation in canopy openness as measured by diffuse and direct

158 beam radiation. 
160 Leaf-level morphological and physiological traits

161 For the non-reproductive life stage, $\mathrm{N}_{\text {area }}$ was consistently higher $(7.8 \%)(P=0.023$, Figure $6 \mathrm{a})$ in

162 the Alliaria weeded treatment as compared to the ambient treatment. There was also a lower $g_{\mathrm{s}}$ in

163 the Alliaria weeded treatment than the ambient treatment for one species (Arisaema; $P<0.028$;

164 Figure 6b), but no change in $g_{\mathrm{s}}$ between treatment for Trillium $(P>0.505$; Figure $6 \mathrm{~b})$ or

165 Maianthemum $\left(P>0.373\right.$; Figure 6b). Combined, these effects resulted in a higher $\mathrm{N}_{\text {area }}$ to $\mathrm{g}_{\mathrm{s}}$

166 ratio in the Alliaria weeded treatment compared to the ambient treatment for all three native

167 plant species $(P=0.018$; Figure $6 \mathrm{c})$. Light-saturated net photosynthesis $\left(\mathrm{A}_{\text {sat }}\right)$ was lower $(20 \%)$ in

168 the Alliaria weeded treatment than the ambient treatment for all three native plants $(P=0.044$;

169 Figure 6d), which, combined with the $N_{\text {area }}$ response, resulted in a lower PNUE (16\%) in the

170 Alliaria weeded treatment than the ambient treatment $(P=0.013 ;$ Figure 6e $)$. The $A_{\text {sat }}$ and $g_{\text {s }}$

171 responses reduced WUE for Arisaema $(P=0.002)$, but not for Maianthemum $(P=0.282)$ or

172 Trillium $(P=0.298)$ in the weeded treatment (Figure 5f). SLA was higher in the Alliaria weeded

173 treatment than the ambient treatment for all three native plants $(P=0.004$; Supplementary Figure

174 1a). Leaf chlorophyll content (Chl) did not differ between treatments for any of the native

175 species $(P=0.150 ;$ Supplementary Figure 1a).

177 For the reproductive life stage, $\mathrm{A}_{\text {sat }}(P=0.004)$ and PNUE $(P=0.019)$ were lower in the weeded

178 versus ambient treatment for Maianthemum. All other morphological and physiology traits did

179 not differ between treatments for any native plant species $(P>0.050)$. 
182 Plant growth differed across plant ontogeny, with smaller individuals growing faster than larger

183 individuals $(P<0.001)$. However, the change in plant size from 2018 to 2019 did not differ

184 between treatments for any of the focal native plant species $(P>0.050$; Supplementary Figure

$1852)$.

187 Discussion

188 Invasive plants are commonly superior resource competitors, reducing soil nutrients to lower

189 levels than can be tolerated by native species. It is becoming increasingly clear that invasion can

190 also disrupt plant-fungal symbionts and reduce nutrient and water provisioning. What so far has

191 remained unclear is the extent to which these invasion-induced changes in belowground

192 dynamics impact aboveground plant traits and performance. Here we provide empirical support

193 for the mutualism disruption hypothesis as a mechanism of invasion success, demonstrating

194 aboveground changes in native plant traits and performance are driven by the disruption of

195 belowground root-fungal symbionts. Specifically, we found no apparent differences in soil

196 nutrient availability after 14-years of Alliaria removal. These results are similar to previous

197 studies, which found little evidence of recovery in abiotic soil properties

198 following Alliaria removal ${ }^{38,39}$. Unlike abiotic soil resources, we find lower AM fungal

199 abundance in the roots of Arisaema and higher soil fungal diversity in the Alliaria ambient

200 treatment. These findings are congruent with previous works, which found plant invasion

201 increased microbial species richness ${ }^{15,38,40}$. Together these results suggest that the main

202 mechanism of Alliaria's impact on native plant performance is mediated through resource

203 provisioning, and not resource availability. 
205 Invasion-induced reductions in soil resource provisioning via mutualism disruption should shift

206 native plant traits linked to carbon and nutrient economies, particularly if resources are limiting.

207 Under nutrient stress, plants may adjust their trait expression to maintain similar leaf-level

208 photosynthetic rates by trading efficient use of abundant resources for that of limiting resources

$209{ }^{30}$. For the first time, our results from our 14-yr experiment support these predictions in an

210 invasion context. We detected divergent morphological and physiological traits for all three focal

211 native species in the weeded and ambient treatments. Specifically, plants in the ambient

212 treatment adopted a resource conservative strategy (low nitrogen concentration and specific leaf

213 area) ${ }^{9}$. We also find evidence that plants in the Alliaria ambient treatment had a higher cost of

214 nitrogen uptake than plants in the Alliaria weeded treatment, as indicated by the greater PNUE

215 and lower ratio of $\mathrm{N}_{\text {area }}$ to $g_{\mathrm{s}}$, consistent with previous results across nutrient availability

216 gradients ${ }^{32}$. For one native species, Arisaema, there was evidence of differential trait investment

217 that increased PNUE and decreased WUE, as would be expected if nutrient availability was more

218 impacted than water availability by Alliaria invasion (Figure 2) ${ }^{30}$. Altogether, this evidence

219 demonstrates that plants in Alliaria invaded sites can maintain carbon fixation by expending

220 more water to compensate for the disruption of root-fungal symbionts and reduced nutrient

221 provisioning. More generally, these results provide some of the first evidence that invasion may

222 drive native plants toward novel regions of their trait space to maintain optimal carbon and

223 nutrient economies. Furthermore, our results suggest trait flexibility underlies a species' ability

224 to withstand invasion-induced resource limitation and may explain the observed variation in

225 mycorrhizal dependency of native plants for maintaining biomass accumulation ${ }^{35}$. However,

226 more research is needed to determine if these changes in plant traits are simply driven by a sheer 
227 decrease in the abundance of beneficial root-fungal associations or a shift in the rate of resource

228 provisioning by effective fungal partners.

229

230 At the whole-plant level, we found high variability in plant growth with small plants increasing

231 in size and large plants decreasing in size on average. Pronounced shrinkage of large individuals

232 is common for species with a high degree of modularity, such as our focal natives, and can be

233 adaptive for delaying senescence and preventing mortality during low resource years (e.g.,

234 drought years) ${ }^{41,42}$. We also found no difference in biomass accumulation between the Alliaria

235 treatments for our focal native species. These results are congruent with our previous work, in

236 which we found no effect of the Alliaria treatment on Trillium's biomass accumulation over a

237 six-year period ${ }^{43}$. Despite no treatment differences in biomass accumulation, we did find a

238 decreased probability of Trillium's reproduction (flowering and fruiting), seedling establishment,

239 and survival between the Alliaria treatments ${ }^{43}$. Those changes in demographic performance

240 translated to a significant decrease (2.3-3.5\%) in Trillium's time-averaged population growth rate

$241 \quad{ }^{43}$. Our results differ from studies on woody species, which found Alliaria invasion suppressed

242 biomass accumulation at the seedling stage ${ }^{44}$. These mixed results suggest invasion may have

243 more pronounced effects on plant growth at the seedling stage and/or may differ among

244 herbaceous versus woody species. The disruption of root-fungal symbionts by Alliaria may also

245 induce trade-offs in resource allocation between life history traits (i.e., size at first reproduction

246 and life time reproductive success) via changes in demographic performance. Globally, our

247 findings empirically demonstrate that some plants can minimize the impacts of invasion in terms

248 of biomass accumulation by employing alternative trait strategies. However, the costs of

249 invasion-induced resource limitation may have stronger negative effects on other demographic 
250 rates, as seen for Trillium ${ }^{43}$. By allocating limiting resources to maintain biomass accumulation, 251 plants may decrease the availability of resources needed for future reproductive output (i.e., the

252 Principle of Allocation $)^{45,46}$. These findings emphasize the need to integrate perspectives from

253 life history theory and ecophysiology to better understand and predict species resistance to

254 invasion-induced shifts in belowground dynamics.

255

256 Methods

257 Study site

258 Our study site is in Fox Chapel, PA (50.520237, -79.900932) in the Trillium Trail Nature

259 Reserve. The experimental design includes five $14 \times 14 \mathrm{~m}$ paired plots subdivided in $362 \times 2 \mathrm{~m}$

260 subplots. Beginning in 2006, we weeded Alliaria every spring from the left side of each plot and

261 carried the weeded material offsite. The right side of each plot was left at ambient Alliaria field

262 densities, resulting in a split plot design. To prevent seed dispersal and re-infestation of Alliaria

263 in subsequent years, we installed temporary mesh barriers between the weeded and ambient sides

264 of the plots prior to Alliaria seed maturation that were removed post seed dispersal each year. All

265 individuals of our three focal native perennial species within the study plots were permanently

266 tagged and monitored annually since the start of the experiment.

268 Non-native invader

269 Alliaria petiolata (Brassicaceae) is a biennial allelochemical-producing herb from Eurasia that 270 invades both disturbed environments and forest interiors throughout North America. Alliaria

271 produces glucosinolates that undergo hydrolysis when released into soils and are converted to 272 cyanide compounds that inhibit respiratory electron transport. These secondary compounds are 
273 toxic to AM fungi ${ }^{36}$, soil pests and pathogens ${ }^{47}$, and insect herbivores ${ }^{48,49}$. A derivative of

274 glucosinolates, allyl isothiocyanate (AITC), inhibits AM fungal spore germination and reduces

275 soil respiration, root colonization, and arbuscule formation in plants associated with AM fungi

$27624,36,44,50,51$. Alliaria invasion often increases soil N, P, Ca, and Mg availability and soil $\mathrm{pH}^{40,52}$.

278 Our previous work demonstrated that Alliaria can have cascading negative effects on the 279 performance and population growth rate of AM dependent understory plant species ${ }^{43}$. We also 280 previously found that Alliaria alters the diversity of native plant communities by reducing the 281 abundance of mycorrhizal plant species, with no subsequent changes in non-mycorrhizal plant 282 species ${ }^{53}$. In support of the mutualism disruption hypothesis, our previous findings suggest

283 Alliaria negatively affects the population- and community-level dynamics of native species 284 through the disruption of plant-microbial interactions.

286 Focal native species

287 The focal natives we used for this study are Arisaema triphyllum (L.), Trillium erectum (L.), and 288 Maianthemum racemosum (L.). These species are long-lived understory forest perennial herbs 289 common in eastern North American temperate forests. The focal species have belowground 290 rhizomes with coarse root systems that lack root hairs and form root-AM fungal symbioses and 291 produce aboveground stems and leaves that senesce annually ${ }^{54}$. The timing and duration of 292 aboveground phenology (period of active photosynthesis) differs among the focal species, with 293 aboveground emergence through senescence spanning April to July for Trillium, May to

294 September for Maianthemum, and April to August for Arisaema ${ }^{55,56}$. Leaves fully expand prior 
295 to canopy closure for Trillium but continue to expand for up to a month following canopy closure 296 for Arisaema and Maianthemum.

298 Soil samples

299 To examine the effects of Alliaria on abiotic soil resources and AM fungal community

300 composition, two subplots within each paired plot were sampled in June 2018 following Burke,

301 et al. ${ }^{39}$. To obtain a sufficient amount of soil (50 g wet weight), five to ten soil cores in each

302 subplot were separated into organic and mineral horizons and pooled separately for a total of 20

303 soil samples (2 Alliaria treatments x 2 soil horizons $\mathrm{x} 5$ plots). The depth of each soil layer per

304 soil core was recorded and the cores were separated into the organic and mineral layers

305 following Burke, et al. ${ }^{39}$.

307 Soil properties

308 To determine soil resource availability, phosphate $\left(\mathrm{PO}_{4}^{-3}\right)$, ammonium $\left(\mathrm{NH}_{4}\right)$, and nitrate $\left(\mathrm{NO}_{3}{ }^{-}\right)$, $309 \mathrm{pH}$, and microbial biomass carbon (MBC) were extracted within $2 \mathrm{~d}$ and soil moisture within $3 \mathrm{~d}$ 310 of soil sampling. Soil moisture was determined gravimetrically as the difference between wet 311 soil and dry soil after drying samples at $105^{\circ} \mathrm{C}$ for two weeks. Soils were extracted in $0.5 \mathrm{M}$ $312 \mathrm{~K}_{2} \mathrm{SO}_{4}$ at a ratio of 1:5 for extractable $\mathrm{PO}_{4}^{-3}, \mathrm{NH}_{4}$ and $\mathrm{NO}_{3}{ }^{-}$and the nutrients were quantified 313 colorimetrically ${ }^{57-59}$. Soil $\mathrm{pH}$ was measured in a 1:2 ratio (w/v) of soil to $\mathrm{H}_{2} \mathrm{O}$ slurry. Soil organic 314 matter was estimated at the plot level by loss-of-ignition method and combusting the soil in a 315 muffle furnace at $360^{\circ} \mathrm{C}^{60}$. Microbial biomass carbon (MBC) was estimated using chloroform 316 fumigation and direct extraction following Brookes, et al. ${ }^{61}$ and expressed as $\mu \mathrm{g} \mathrm{C}$ per $\mathrm{g}$ of dry 317 soil and is corrected for extraction efficiency (0.45). To assess the length of AM fungal hyphae 
318 in the organic and mineral layers, hyphae were extracted from $5 \mathrm{~g}$ of soil in $5 \%$ sodium

319 hexametaphosphate, filtered through nylon filter ( $47-\mathrm{mm}$ diameter, $0.45-\mu \mathrm{m}$ pore size) and

320 stained with acid fuschin ${ }^{15}$. The stained hyphae were visualized and scored using the grid-line

321 intersect method ${ }^{62}$ in 50 grids at $200 \mathrm{X}$ and the hyphal length was calculated as mm hyphae per $\mathrm{g}$

322 of dry soil. To capture the average soil properties near the focal native plant roots, we used the

323 average proportion of each soil layer in each subplot to calculate the weighted mean soil

324 properties (i.e., total bulk soil). Overall, the depths of the soil cores before hitting claypan or

325 rock ranged from 2.93 to $15.00 \mathrm{~cm}$, with a mean depth of $11.26 \mathrm{~cm}$.

327 Soil AM fungal communities

328 To determine differences in AM fungal composition across Alliaria treatments, DNA was

329 extracted from $500 \mathrm{mg}$ of soil using a Power Soil DNA Isolation Kit (MO BIO Laboratories, CA,

330 USA). DNA was quantified using a Qubit Fluorometer and stored at $-80^{\circ} \mathrm{C}$. To analyze the AM

331 fungal community composition, a nested PCR approach was used to first amplify a 1200 base

332 pair region of the $18 \mathrm{~S}$ fungal DNA using NL1-NL4 eukaryotic primers ${ }^{63}$. Each PCR contained

$33321.5 \mu 1$ of Platinum PCR Supermix (Invitrogen, Carlsbad, CA, USA), $1.25 \mu 1$ of each primer (10

$334 \mu \mathrm{M}), 0.5 \mu 1$ of BSA $\left(20 \mathrm{mg} \mathrm{ml}^{-1}\right)$, and $2 \mu 1(\sim 20 \mathrm{ng})$ of DNA. The reactions for the first PCR

335 with NS1 and NS4 primers ran with a hot start at $94{ }^{\circ} \mathrm{C}$ for $3 \mathrm{~min}$, followed by 30 cycles of 94

$336{ }^{\circ} \mathrm{C}$ for $30 \mathrm{~s}, 58{ }^{\circ} \mathrm{C}$ for $60 \mathrm{~s}$, and $72{ }^{\circ} \mathrm{C}$ for $60 \mathrm{~s}$ and a final extension step of $72{ }^{\circ} \mathrm{C}$ for $10 \mathrm{~min}$. A 2

$337 \mu 1$ aliquot of the PCR product from this PCR was used as template for the AM fungal-specific

338 PCR using the NS31 and AM1 primers ${ }^{64,65}$. The reaction volumes were identical to the first

339 PCR. The reactions ran with a hot start at $94{ }^{\circ} \mathrm{C}$ for $5 \mathrm{~min}$, followed by 40 cycles of $94{ }^{\circ} \mathrm{C}$ for 45

$340 \mathrm{~s}, 63.1^{\circ} \mathrm{C}$ for $60 \mathrm{~s}$, and $72{ }^{\circ} \mathrm{C}$ for $90 \mathrm{~s}$ and a final extension step of $72{ }^{\circ} \mathrm{C}$ for $10 \mathrm{~min}$. The PCR 
341 with AM fungal-specific primers were run in triplicate, combined, cleaned with Agencourt

342 AMPure XP magnetic beads (Beckman Coulter, Brea, CA) and quantified with a Qubit

343 fluorometer. Each sample was sequenced in a paired end 2 x $275 \mathrm{~b}$ run on an Illumina MiSeq at

344 the University of Tennessee Genomics Core. All sequences are deposited in the NCBI SRA with

345 accession number (released upon publication). Contigs of forward and reverse sequences were

346 created using the DADA2 pipeline using default parameters ${ }^{66}$.

348 AM fungal root colonization

349 To characterize differences in AM fungal colonization in native plant roots between the Alliaria

350 treatments, we collected root samples for each focal native species in June of 2018 ( $N=53 ; 3-13$

351 individuals x 3 native plant species x 2 Alliaria treatments). To control for variation in root

352 colonization across plant ontogeny, we restricted our samples to large non-flowering individuals.

353 Roots were cleared and stained following McGonigle, et al. ${ }^{67}$ and the presence or absence of

354 AM fungal structures (i.e., arbuscules or aseptate hyphae) were counted across 60-125

355 intersections at 200x.

357 Leaf-level morphological and physiological traits

358 To characterize the effect of the Alliaria treatments on morphological and physiological traits

359 associated with water and nutrient use efficiency for the focal native understory species, we

360 quantified the instantaneous physiology of a subset of reproductive and non-reproductive plants

361 in $2018(\mathrm{~N}=468 ; 29-57$ individuals x 2 Alliaria treatments $\times 3$ species $\times 2$ life stages $)$. We

362 measured the net photosynthetic rate $\left(\mathrm{A}_{\mathrm{sat}}\right)$, and stomatal conductance $\left(\mathrm{g}_{\mathrm{s}}\right)$ using a Li-COR LI-

363 6400XTR portable photosynthesis system, equipped with a $\mathrm{CO}_{2}$ control module, $2 \times 3 \mathrm{~cm}$ leaf 
364 cuvette and a red-blue light-emitting diode (LED) light source (Li-Cor, Lincoln, NE, USA).

365 Measurements were taken at a saturating light level of $800 \mu \mathrm{mol} \mathrm{m}^{-2} \mathrm{~s}^{-1}$, ambient temperature and

366 humidity, and a reference chamber $\mathrm{CO}_{2}$ concentration of $400 \mu \mathrm{mol} \mathrm{mol}{ }^{-1}$, following Heberling, et

367 al. ${ }^{68}$. To minimize within-plant variability for Maianthemum, we restricted our sampling to

368 either the $2^{\text {nd }}$ or $3^{\text {rd }}$ leaf from the terminal end of the stem following Cornelissen, et al. ${ }^{69}$ and only

369 used leaves without signs of senescence or damage (e.g. insect herbivory). Specific leaf area

370 (SLA) and leaf carbon and nitrogen concentration were measured on a subset of individuals (11-

37118 individuals x 2 Alliaria treatments x 3 species x 2 life stages). To measure SLA, we collected

372 two to three $5.32 \mathrm{~cm}^{2}$ leaf tissue samples from each individual and calculated the mean leaf

373 surface area per g dry mass $\left(\mathrm{cm}^{2} \mathrm{~g}^{-1}\right)$. Leaf carbon and nitrogen concentration were measured on

374 dry leaf samples using an elemental analyzer (Costech Inc., Valencia, CA). We used these

375 physiological measurements to calculate water use efficiency (WUE) $\left(\mathrm{A}_{\text {sat }} / \mathrm{g}_{\mathrm{s}}\right)$, photosynthetic

376 nitrogen use efficiency (PNUE) $\left(\mathrm{A}_{\text {sat }} /\right.$ percent nitrogen $*$ SLA), and nitrogen per leaf area $\left(\mathrm{N}_{\text {area }}\right)$

377 for a given rate of stomatal conductance $\left(\mathrm{g}_{\mathrm{s}}\right)$. The mean chlorophyll content $(\mathrm{Chl})$ of three

378 leaflets per plant was measured using a SPAD 502 Chlorophyll Meter (spectrum Technologies,

379 Inc, Aurora, IL, USA); (N=284; $34-57$ individuals x 3 species x 2 Alliaria treatments x 2 life

380 stages). To standardize our sampling, we chose to measure Chl from the darkest green section of

381 each leaflet. The Chl-sampled individuals are a subset of plants for which the other functional

382 traits were measured and the same plants for which whole-plant performance were measured

383 (below).

384

385 Light availability and canopy openness 
386 To test if focal species' trait characteristics were driven by differences in ambient light levels in

387 the Alliaria ambient and weeded treatments, we took hemispherical $180^{\circ}$ image digital

388 photographs with a Pentax K-50 camera fitted with a Lensbaby ${ }^{\mathrm{TM}}$ circular fisheye lens. To take

389 the photographs, the camera was held $\sim 80 \mathrm{~cm}$ above the forest floor on a tripod in the center of

390 each subplot in which functional trait data were collected. The camera was set to the full wide-

391 angle mode, with the flash and macro setting turned off. To maintain consistent image alignment,

392 we standardized the directionality of each photograph (e.g., top of photograph facing North and

393 left side facing West). Photographs were post-processed and analyzed using Gap Light Analyzer

3942.0 software to calculate the gap light index ${ }^{70}$, a metric of diffuse and direct beam radiation.

396 Whole-plant performance

397 To capture the effect of the Alliaria treatment on plant growth, we selected $\mathrm{N}=501$ individuals

398 across the three species and measured aboveground size in June-July in 2018 and 2019. Plant

399 biomass was estimated using species-specific allometric equations previously developed ${ }^{43,71,72}$.

\section{$401 \quad$ Statistical analysis}

\section{Soil properties}

403 To evaluate the effects of the Alliaria ambient and weeded treatment on abiotic soil

404 concentrations of $\mathrm{PO}_{4}^{-3}, \mathrm{NH}_{4}, \mathrm{NO}_{3}, \mathrm{MBC}$, and the biomass of fungal hyphae, we conducted

405 univariate analyses for each variable separately using a generalized linear mixed effect model.

406 To improve normality of the residuals, $\mathrm{PO}_{4}^{-3}$ and soil moisture were square root transformed and

$407 \mathrm{pH}, \mathrm{NH}_{4} \mathrm{NO}_{3}{ }^{-}$, and $\mathrm{MBC}$ were natural log transformed. 
410 To characterize differences in alpha diversity between treatments, we calculated the Shannon-

411 Wiener index and Simpson diversity index. To test for significant differences in Shannon-

412 Wiener, we used a linear mixed effect model and for the Simpson index we used a mixed effect

413 model with a beta distribution. To capture differences in the soil fungal community composition

414 between the Alliaria treatments based on species abundance, we used a permutation multivariate

415 analysis of variance (PERMANOVA) using the vegan package and the adonis function

\section{AM fungal root colonization}

418 To quantify differences in the 2018 root colonization rates of AM fungi between the Alliaria

419 ambient and weeded treatments, we used a beta regression model ${ }^{73}$. For each model, we

420 included the Alliaria treatment, the focal native species, and an interaction term as a fixed effect.

421 The response variable for each model was the proportion of arbuscules or aseptate hyphae

422 present across 60-125 fields of view.

\section{Leaf-level morphological and physiological traits}

425 To evaluate the effect of the Alliaria treatments on the morphological and physiological traits,

426 we conducted univariate analyses for each trait separately using a linear mixed effects model.

427 The fully parameterized models included the Alliaria (ambient or weeded) treatment, the focal

428 native species (Arisaema, Maianthemum, and Trillium), initial plant size (2018), and a treatment

429 by species interaction term as predictor variables. The response variables were $\mathrm{A}_{\text {sat }}, \mathrm{Chl}$, WUE,

$430 \mathrm{~g}_{\mathrm{s}}, \mathrm{SLA}$, PNUE, $\mathrm{N}_{\text {area }}$, and $\mathrm{N}_{\text {area }} / \mathrm{g}_{\mathrm{s}}$. Examining differences in morphological and physiological

431 traits for the reproductive life stage was not possible for Arisaema because few individuals 
432 flowered in 2018 , so the morphological and physiological traits for reproductive and non-

433 reproductive life stages were analyzed separately. To improve nonnormality of the residuals, we $434 \log$ transformed PNUE WUE, and $\mathrm{g}_{\mathrm{s}}$.

436 Light availability and canopy openness

437 To test for differences in light availability between Alliaria ambient or weeded treatment, we 438 calculated the gap light index and applied a generalized linear model. The fully parameterized 439 model included the Alliaria treatment as the predictor variable and the total diffuse and direct 440 beam radiation as the response variable.

\section{Whole-plant performance}

443 To examine if the Alliaria treatments influenced plant growth of our focal native species, we

444 used a linear mixed model. To improve nonlinearity, size at time $\mathrm{t}_{2018}$ and $\mathrm{t}_{2019}$ were log

445 transformed. The fully parameterized models included the Alliaria (ambient and weeded)

446 treatment and initial plant size as fixed effects.

448 All statistical analyses were conducted in R v. 3.4.3 ${ }^{74}$. Generalized linear models were fit using 449 the $g \mathrm{~lm}$ function and generalized linear mixed models were fit using the $l \mathrm{mer}$ and $g \mathrm{lmer}$ 450 functions in package 1 me $4{ }^{75}$. To account for the nested experimental design and non-random 451 spatial structure, we included treatment nested within plot as a random factor in our regression 452 models. To test for significant main effects and interaction terms, we used backward stepwise 453 regression. Non-significant interactions and main effects were dropped sequentially, removing 454 non-significant interaction terms first. Comparisons between the fully parameterized models and 
455 reduced models were made using a likelihood ratio test. Significant differences were determined 456 using type III analysis of deviance for interactions and type II for main effects, using the Anova 457 function in the car package ${ }^{76}$. To identify significant difference between factor levels, we 458 calculated differences of least squares means and confidence intervals using the lmerTest 459 package and the difflsmeans function ${ }^{77}$. 


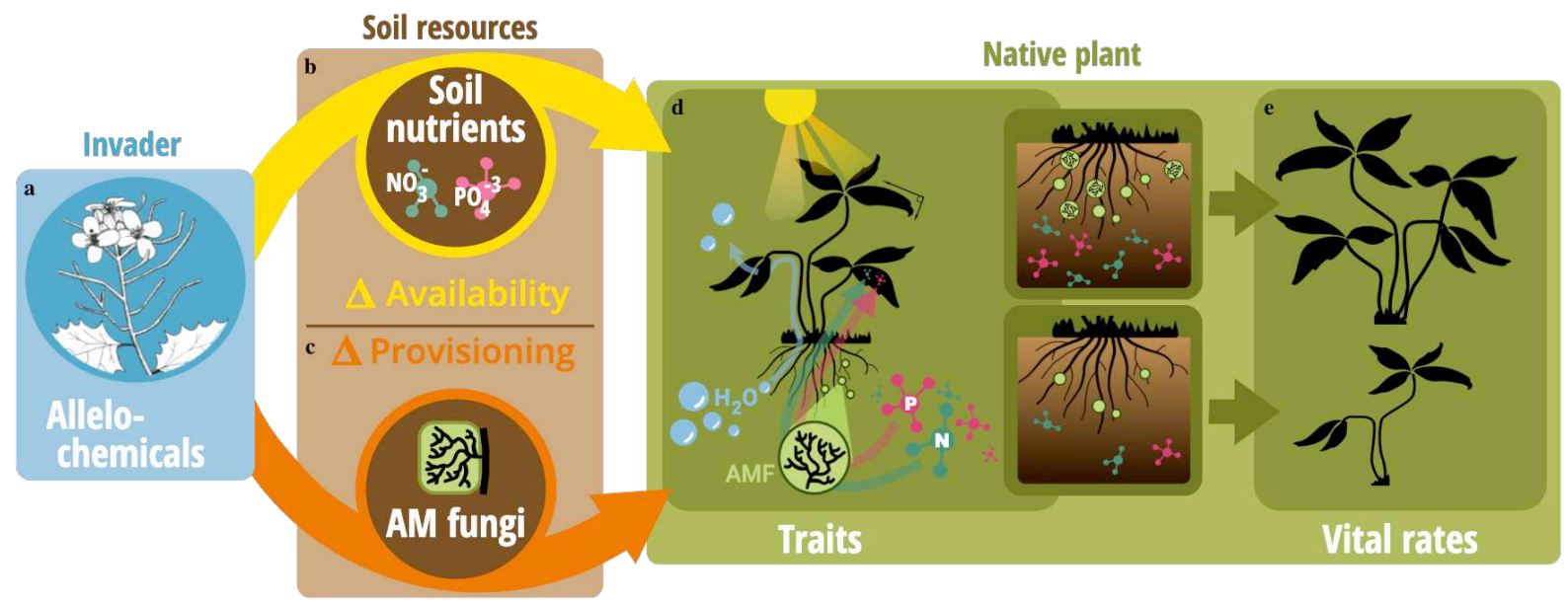

472

473 Figure 1: Invasive plants can lead to resource limitation through the depletion of soil resources (panel b) or the disruption of mutualistic interactions respectively (panel c). These alternative or concurrent

475

476

477

478

479

480

481

482

483

484

485

486

487

488

489

490 


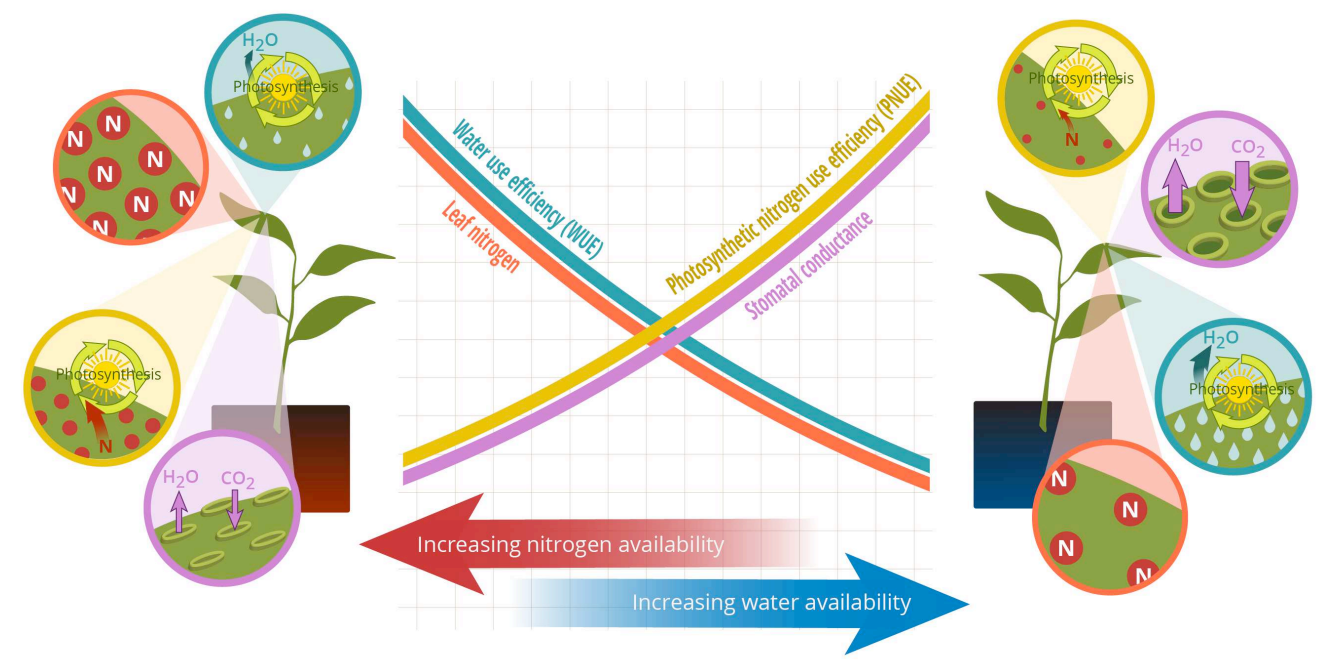

491

492

493

494

495

496

497

498

499

500

501

502

503

504

505

506
Figure 2: Plant responses to altered nutrient and water availability and/or provisioning. Plants tend to increase stomatal conductance and decrease leaf nitrogen in low nutrient environments and vice versa in low water environments. In order to maintain similar leaf-level photosynthetic rates in low resource environments, plants can trade the efficient use of abundant resources for that of limiting resources. For example, plants in nutrient limited environments can increase PNUE and decrease WUE. These tradeoffs lead to the prediction that plants under high nutrient stress will decrease leaf nitrogen per area at a given stomatal conductance. 

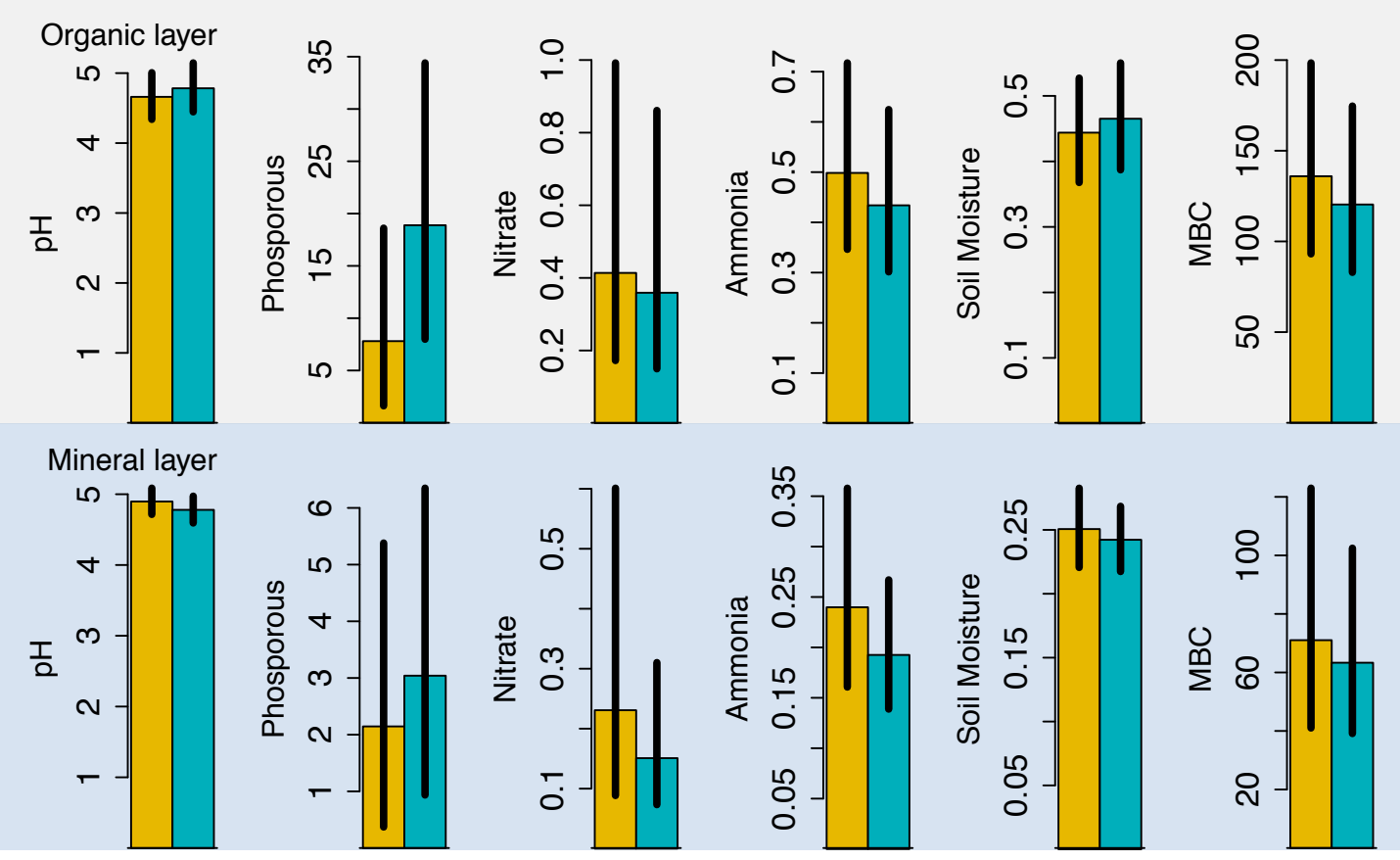

Figure 3: Soil properties in the organic (top) and mineral (bottom) layers. All soil properties were 


\section{Organic layer}
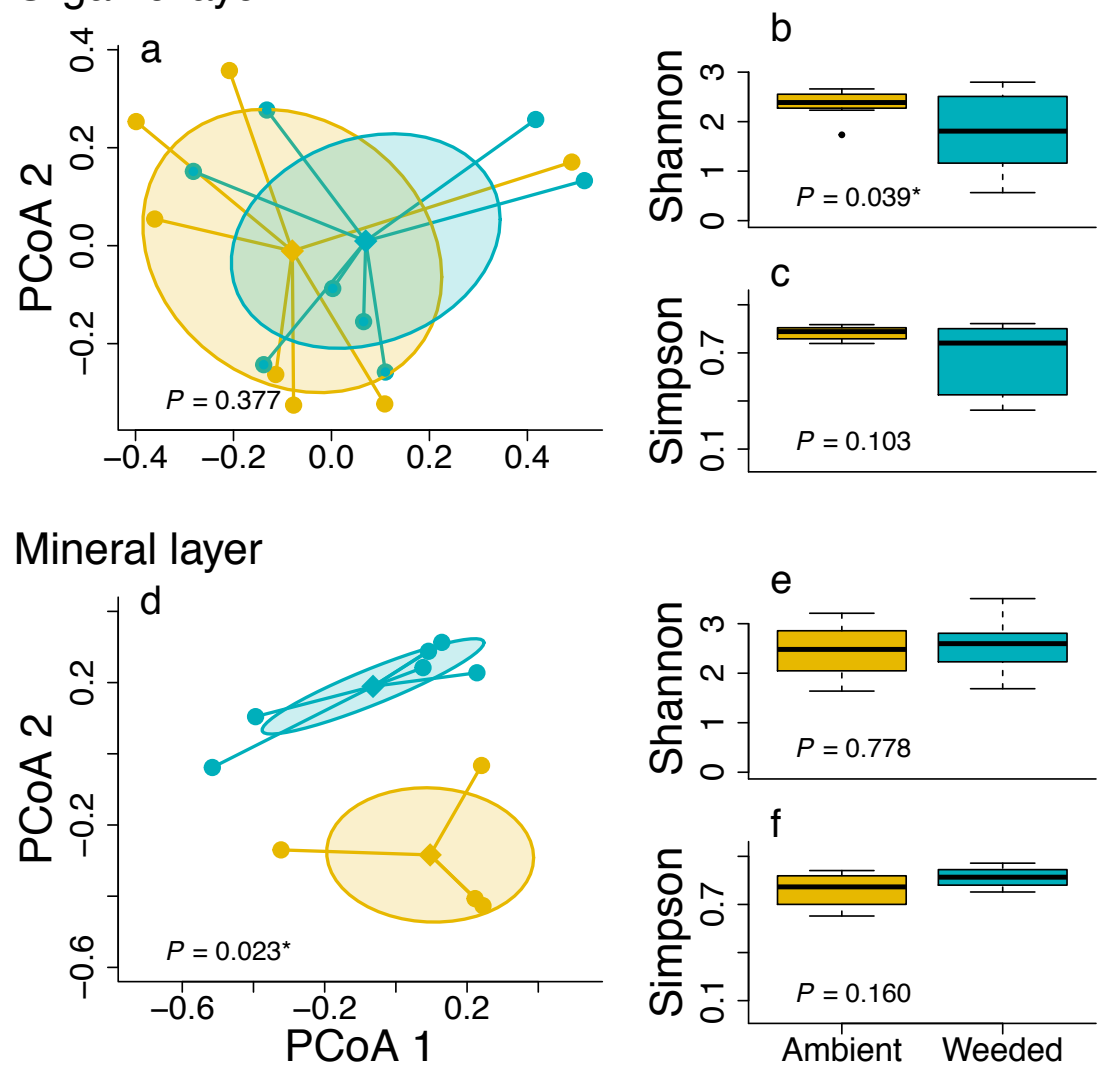

512 Figure 4: Comparison of Alliaria treatment effects (ambient or weeded) on soil fungal

513 community beta (a, d) and alpha diversity (b, c, e , f) for two soil layers: organic (top) and

514 mineral (bottom). The Principal Coordinates Analysis graphs (left) illustrate the similarity or 515 dissimilarity (beta diversity) of the soil fungal community between treatments based on species 516 abundance. The graphs to the right show differences in soil fungal Shannon-Wiener diversity and 517 Simpson Index between the ambient (gold) and weeded (teal) treatments. 

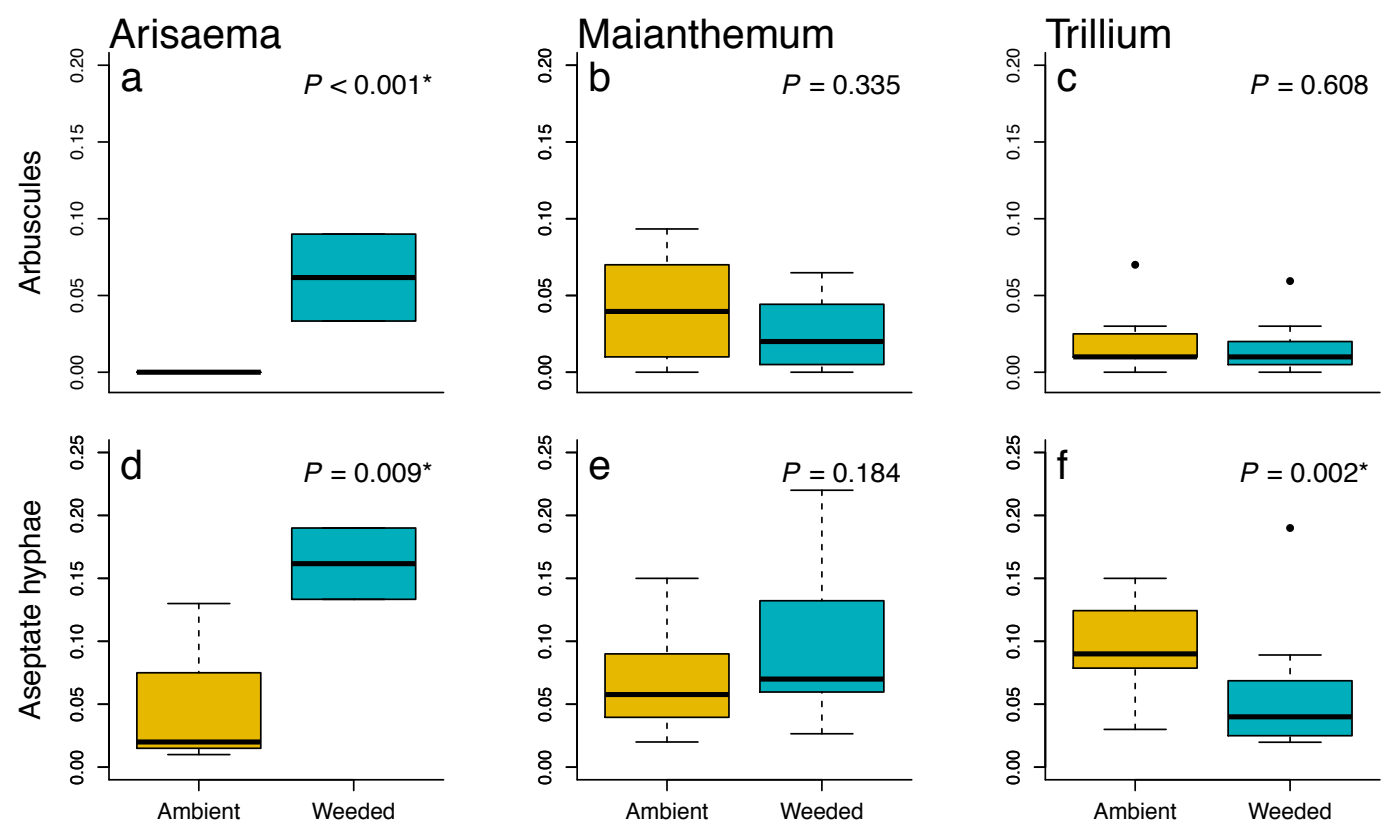

Treatment

520 Figure 5: Root colonization of the focal native perennials (Arisaema, Maianthemum, and

521 Trillium) in the Alliaria ambient and weeded treatments in 2018. The response variable was the 522 523 proportion of arbuscules or aseptate hyphae present across 60-125 fields of view. 

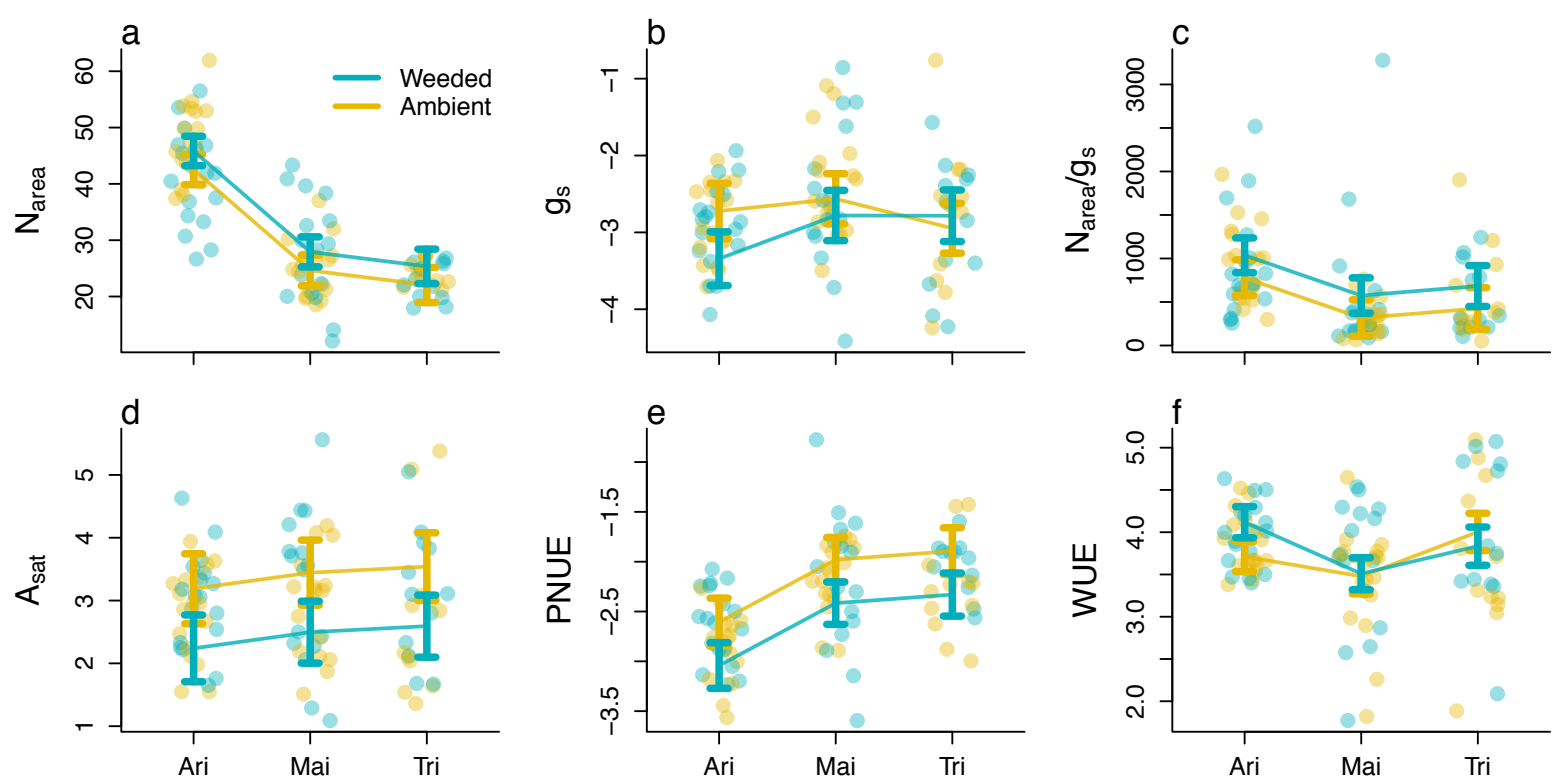

Figure 6: Physiological traits and resource use efficiencies for the non-reproductive life stage in the Alliaria weeded (teal) and ambient (gold) treatments. The interaction term between the Alliaria treatment and species is significant at $P=0.05$ for WUE and $\mathrm{g}_{\mathrm{s}}$. The main effect of treatment is significant for $\mathrm{A}_{\text {sat }}, \mathrm{PNUE}, \mathrm{N}_{\text {area }}$, and $\mathrm{N}_{\text {area }} / \mathrm{g}_{\mathrm{s}}$. 


\section{References}

5331 Wilcove, D. S., Rothstein, D., Dubow, J., Phillips, A. \& Losos, E. Quantifying threats to imperiled species in the United States. BioScience 48, 607-615 (1998). of exotic understory plants in deciduous forests. Ecological Applications 11, 1287-1300 (2001).

3 Davis, M. A., Grime, J. P. \& Thompson, K. Fluctuating resources in plant communities: a general theory of invasibility. Journal of Ecology 88, 528-534 (2000).

4 Traveset, A. \& Richardson, D. M. Mutualistic interactions and biological invasions. Annual Review of Ecology, Evolution, and Systematics 45, 89-113 (2014).

5 Blumenthal, D. M. Interactions between resource availability and enemy release in plant invasion. Ecology Letters 9, 887-895 (2006).

6 Zhang, P., Li, B., Wu, J. \& Hu, S. Invasive plants differentially affect soil biota through litter and rhizosphere pathways: a meta-analysis. Ecology Letters 22, 200-210 (2019).

7 Allison, S. D. \& Vitousek, P. M. Rapid nutrient cycling in leaf litter from invasive plants in Hawai'i. Oecologia 141, 612-619 (2004).

8 Johnson, N. C. Resource stoichiometry elucidates the structure and function of arbuscular mycorrhizas across scales. New Phytologist 185, 631-647 (2010).

9 Funk, J. L. The physiology of invasive plants in low-resource environments. Conservation Physiology 1 (2013).

10 Tilman, D. Resource competition and community structure. (Princeton university press, 1982).

11 Reinhart, K. O. \& Callaway, R. M. Soil biota and invasive plants. New Phytologist 170, 445-457 (2006).

12 Dawson, W. \& Schrama, M. Identifying the role of soil microbes in plant invasions. Journal of Ecology 104, 1211-1218 (2016).

13 Husband, R., Herre, E. A., Turner, S., Gallery, R. \& Young, J. Molecular diversity of arbuscular mycorrhizal fungi and patterns of host association over time and space in a tropical forest. Molecular Ecology 11, 2669-2678 (2002).

14 Vandenkoornhuyse, P. et al. Arbuscular mycorrhizal community composition associated with two plant species in a grassland ecosystem. Molecular Ecology 11, 1555-1564 (2002).

15 Kivlin, S. N. \& Hawkes, C. V. Differentiating between effects of invasion and diversity: impacts of aboveground plant communities on belowground fungal communities. New Phytologist 189, 526-535 (2011).

16 van der Putten, W. H. Impacts of soil microbial communities on exotic plant invasions. Trends in Ecology \& Evolution 25, 512-519 (2010).

17 Hierro, J. L. \& Callaway, R. M. Allelopathy and exotic plant invasion. Plant and Soil 256, 29-39 (2003).

18 Wang, W. et al. Nutrient exchange and regulation in arbuscular mycorrhizal symbiosis. Molecular Plant 10, 1147-1158 (2017).

19 Soudzilovskaia, N. A. et al. FungalRoot: global online database of plant mycorrhizal associations. New Phytologist (2020). 
20 Drigo, B. et al. Shifting carbon flow from roots into associated microbial communities in response to elevated atmospheric CO2. Proceedings of the National Academy of Sciences 107, 10938-10942 (2010).

21 Parniske, M. Arbuscular mycorrhiza: the mother of plant root endosymbioses. Nature Reviews Microbiology 6, 763-775 (2008).

58022 Smith, S. E., Smith, F. A. \& Jakobsen, I. Mycorrhizal fungi can dominate phosphate

23 Yang, S.-Y. et al. Nonredundant regulation of rice arbuscular mycorrhizal symbiosis by two members of the PHOSPHATE TRANSPORTER1 gene family. The Plant Cell 24, 4236-4251 (2012).

24 Hale, A. N. \& Kalisz, S. Perspectives on allelopathic disruption of plant mutualisms: a framework for individual-and population-level fitness consequences. Plant Ecology 213, 1991-2006 (2012).

25 Poorter, H., Niinemets, Ü., Poorter, L., Wright, I. J. \& Villar, R. Causes and consequences of variation in leaf mass per area (LMA): a meta-analysis. New Phytologist 182, 565-588 (2009).

26 Firn, J. et al. Leaf nutrients, not specific leaf area, are consistent indicators of elevated nutrient inputs. Nature Ecology \& Evolution 3, 400-406 (2019).

27 Lin, Y.-S. et al. Optimal stomatal behaviour around the world. Nature Climate Change 5, 459-464 (2015).

28 Prentice, I. C., Dong, N., Gleason, S. M., Maire, V. \& Wright, I. J. Balancing the costs of carbon gain and water transport: testing a new theoretical framework for plant functional ecology. Ecology Letters 17, 82-91 (2014).

29 Prentice, I. C. et al. Evidence of a universal scaling relationship for leaf CO2 drawdown along an aridity gradient. New Phytologist 190, 169-180 (2011).

30 Wright, I. J., Reich, P. B. \& Westoby, M. Least-cost input mixtures of water and nitrogen for photosynthesis. The American Naturalist 161, 98-111 (2003).

31 Wright, I. J. et al. Modulation of leaf economic traits and trait relationships by climate. Global Ecology and Biogeography 14, 411-421 (2005).

32 Paillassa, J. et al. When and where soil is important to modify the carbon and water economy of leaves. New Phytologist (2020).

33 Harpole, W. S. et al. Out of the shadows: multiple nutrient limitations drive relationships among biomass, light and plant diversity. Functional Ecology 31, 1839-1846 (2017).

34 Wu, Z., Dijkstra, P., Koch, G. W., Peñuelas, J. \& Hungate, B. A. Responses of terrestrial ecosystems to temperature and precipitation change: A meta-analysis of experimental manipulation. Global Change Biology 17, 927-942 (2011).

35 Rodgers, V. L., Stinson, K. A. \& Finzi, A. C. Ready or not, garlic mustard is moving in: Alliaria petiolata as a member of eastern North American forests. AIBS Bulletin 58, 426436 (2008).

36 Cantor, A., Hale, A., Aaron, J., Traw, M. B. \& Kalisz, S. Low allelochemical concentrations detected in garlic mustard-invaded forest soils inhibit fungal growth and AMF spore germination. Biological Invasions 13, 3015-3025 (2011).

618 Brundrett, M. \& Kendrick, B. The roots and mycorrhizas of herbaceous woodland plants: II. Structural aspects of morphology. New Phytologist 114, 469-479 (1990). 
38 Anthony, M., Stinson, K., Trautwig, A., Coates-Connor, E. \& Frey, S. Fungal communities do not recover after removing invasive Alliaria petiolata (garlic mustard).

\section{Biological Invasions 21, 3085-3099 (2019).}

39 Burke, D. J. et al. Deer and invasive plant removal alters mycorrhizal fungal communities and soil chemistry: Evidence from a long-term field experiment. Soil Biology and Biochemistry 128, 13-21 (2019).

40 Anthony, M., Frey, S. \& Stinson, K. Fungal community homogenization, shift in dominant trophic guild, and appearance of novel taxa with biotic invasion. Ecosphere 8, e01951 (2017).

41 Horvitz, C. C. \& Schemske, D. W. Spatiotemporal variation in demographic transitions of a tropical understory herb: projection matrix analysis. Ecological Monographs 65, 155-192 (1995).

42 Salguero-Gómez, R. \& Casper, B. B. Keeping plant shrinkage in the demographic loop. Journal of Ecology 98, 312-323 (2010).

43 Bialic-Murphy, L. B. N. K. S. Direct effects of a non-native invader erode native plant fitness in the forest understory. Journal of Ecology 108, 189-198, doi:10.1111/13652745.13233 (2019).

44 Stinson, K. A. et al. Invasive plant suppresses the growth of native tree seedlings by disrupting belowground mutualisms. PLoS biology 4 (2006).

45 Levins, R. Evolution in changing environments: some theoretical explorations. (Princeton University Press, 1968).

Obeso, J. R. The costs of reproduction in plants. New Phytologist 155, 321-348 (2002).

4 Brown, P. D. Control of soil-borne plant pests using glucosinolate-containing plants. Adv. Agron. 61, 168-231 (1997).

48 Chew, F. Searching for Defensive Chemistry in the Cruciferae, or, Do Glucosinolates Always. Chemical Mediation of Coevolution, 81 (1988).

49 Porter, A. Implications of introduced garlic mustard (Alliaria petiolata) in the habitat of Pieris virginiensis (Pieridae). Journal of the Lepidopterists' Society 48, 171-172 (1994).

50 Hale, A. N., Lapointe, L. \& Kalisz, S. Invader disruption of belowground plant mutualisms reduces carbon acquisition and alters allocation patterns in a native forest herb. New Phytologist 209, 542-549 (2016).

51 Hale, A. N., Tonsor, S. J. \& Kalisz, S. Testing the mutualism disruption hypothesis: physiological mechanisms for invasion of intact perennial plant communities. Ecosphere 2, 1-15 (2011).

52 Rodgers, V. L., Wolfe, B. E., Werden, L. K. \& Finzi, A. C. The invasive species Alliaria petiolata (garlic mustard) increases soil nutrient availability in northern hardwood-conifer forests. Oecologia 157, 459-471 (2008).

53 Roche, M. D. et al. Negative effects of an allelopathic invader on AM fungal plant species drive community-level responses. In review. (2020).

54 Brundrett, M. C. \& Kendrick, B. The mycorrhizal status, root anatomy, and phenology of plants in a sugar maple forest. Canadian Journal of Botany 66, 1153-1173 (1988).

55 Heberling, J. M., Cassidy, S. T., Fridley, J. D. \& Kalisz, S. Carbon gain phenologies of spring-flowering perennials in a deciduous forest indicate a novel niche for a widespread invader. New Phytologist 221, 778-788 (2019). 
Heberling, J. M., McDonough MacKenzie, C., Fridley, J. D., Kalisz, S. \& Primack, R. B. Phenological mismatch with trees reduces wildflower carbon budgets. Ecology Letters 22, 616-623 (2019). determination of phosphate in water and soil. Journal of Environmental Quality 30, 22062209 (2001).

58 Lajitha, K., Driscoll, C., Jarrell, W. \& Elliot, E. in In Robertson G et al. Standard soil methods for long-term ecological research (1999).

59 Doane, T. A. \& Horwáth, W. R. Spectrophotometric determination of nitrate with a

single reagent. Analytical Letters 36, 2713-2722 (2003).

60 David, M. B. Use of loss-on-ignition to assess soil organic carbon in forest soils. Communications in Soil Science and Plant Analysis 19, 1593-1599 (1988).

61 Brookes, P., Landman, A., Pruden, G. \& Jenkinson, D. Chloroform fumigation and the release of soil nitrogen: a rapid direct extraction method to measure microbial biomass nitrogen in soil. Soil Biology and Biochemistry 17, 837-842 (1985).

62 Brundrett, M. C. \& Abbott, L. Mycorrhizal fungus propagules in the Jarrah forest: II. spatial variability in inoculum levels. New Phytologist 131, 461-469 (1995). O'Donnell, K. in The fungal holomorph: mitotic, meiotic and pleomorphic speciation in

\section{(65) Kivlin, S. N. \& Hawkes, C. V. T1} fungal systematics (eds DR Reynolds \& JW Taylor) 225-233. (CAB International, 1993). soil fungal abundance, richness, and composition in Neotropical rainforests.

66 Callahan, B. J. et al. DADA2: high-resolution sample inference from Illumina amplicon data. Nature Methods 13, 581 (2016).

67 McGonigle, T., Miller, M., Evans, D., Fairchild, G. \& Swan, J. A new method which gives an objective measure of colonization of roots by vesicular-arbuscular mycorrhizal fungi. New Phytologist 115, 495-501 (1990).

68 Heberling, M. J., Brouwer, N. L. \& Kalisz, S. Effects of deer on the photosynthetic performance of invasive and native forest herbs. AoB PLANTS (2017).

69 Cornelissen, J. et al. A handbook of protocols for standardised and easy measurement of plant functional traits worldwide. Australian Journal of Botany 51, 335-380 (2003).

70 Frazer, G. W., Canham, C. \& Lertzman, K. Gap Light Analyzer (GLA), Version 2.0: Imaging software to extract canopy structure and gap light transmission indices from true-colour fisheye photographs, users manual and program documentation. Simon Fraser University, Burnaby, British Columbia, and the Institute of Ecosystem Studies, Millbrook, New York 36 (1999).

71 Brouwer, N. L., Hale, A. N. \& Kalisz, S. Mutualism-disrupting allelopathic invader drives carbon stress and vital rate decline in a forest perennial herb. AoB Plants 7 (2015).

72 Bialic-Murphy, L., Heckel, C. D., McElderry, R. M. \& Kalisz, S. Deer indirectly alter the reproductive strategy and operational sex ratio of an unpalatable forest perennial. The

70873 Crawley, M. The R Book.,(Wiley: Chichester, UK.). (2007). 
70974 R Developement Core Team. R: A language and environment for statistical computing. R 710 Foundation for Statistical Computing, Vienna, Austria. . (2013).

$71175 \quad$ Bates, D., Maechler, M., Bolker, B. \& Walker, S. (2009).

$71276 \quad$ Fox, J. et al. The car package. R Foundation for Statistical Computing (2007).

71377 Kuznetsova, A., Brockhoff, P. B. \& Christensen, R. H. lmerTest package: tests in linear

714

715 mixed effects models. Journal of Statistical Software 82, 1-26 (2017).

716

717

718

719

720 


\section{Figures}

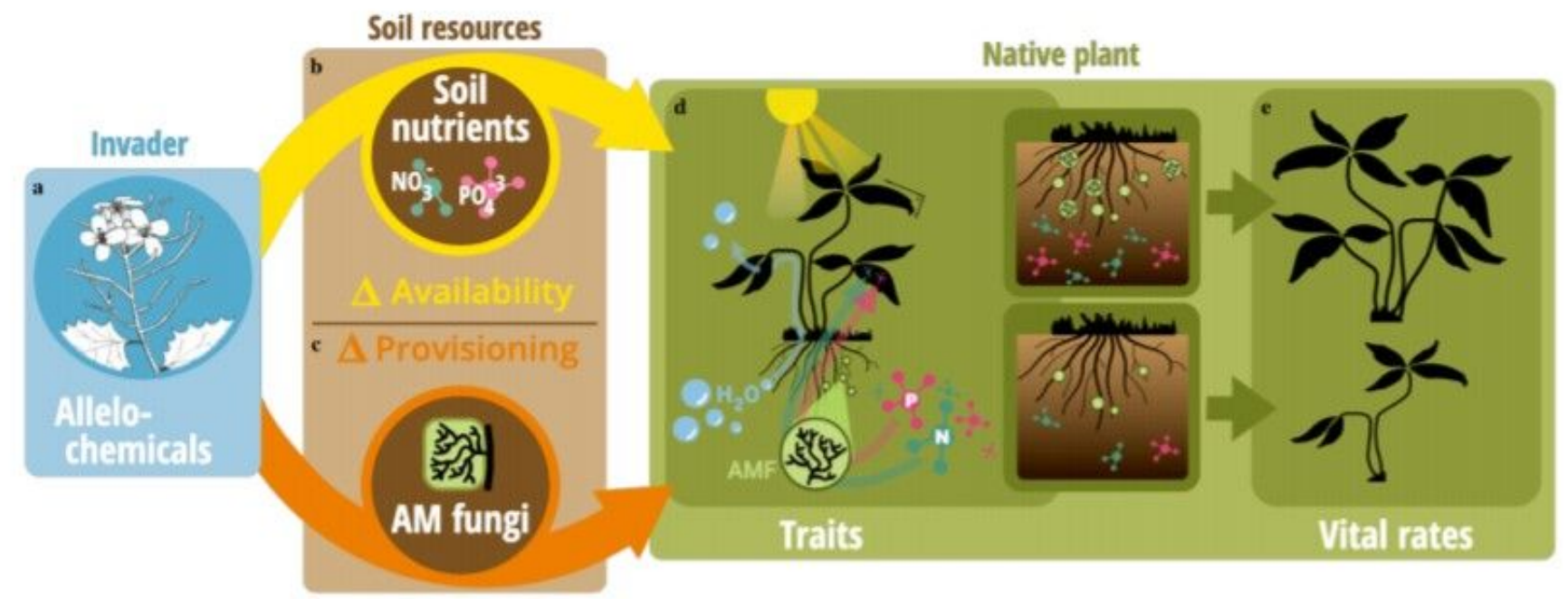

\section{Figure 1}

Invasive plants can lead to resource limitation through the depletion of soil resources (panel b) or the disruption of mutualistic interactions respectively (panel c). These alternative or concurrent pathways of invasion-induced resource limitation can be detected as a shift in native plant traits linked to their carbon and nutrient economies (panel d). Plants that can adjust their trait space to maintain leaf-level photosynthetic output are likely to the least impacted by invasion. However, metrics of whole-plant performance (i.e., survival, growth, and reproduction) can be constrained if resources necessary to build new tissues are significantly limited (panel e). 


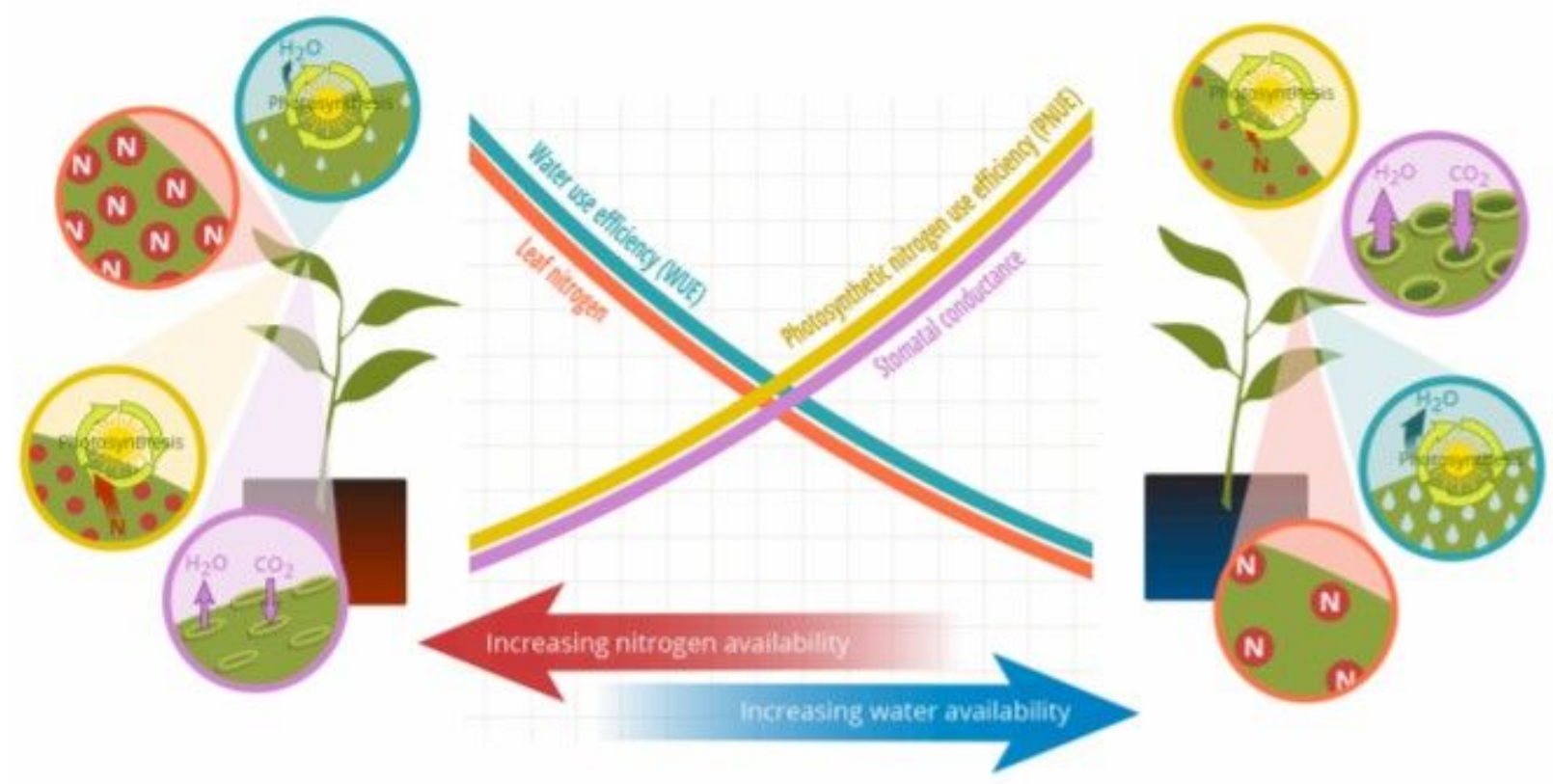

Figure 2

Plant responses to altered nutrient and water availability and/or provisioning. Plants tend to increase stomatal conductance and decrease leaf nitrogen in low nutrient environments and vice versa in low water environments. In order to maintain similar leaf-level photosynthetic rates in low resource environments, plants can trade the efficient use of abundant resources for that of limiting resources. For example, plants in nutrient limited environments can increase PNUE and decrease WUE. These tradeoffs lead to the prediction that plants under high nutrient stress will decrease leaf nitrogen per area at a given stomatal conductance. 


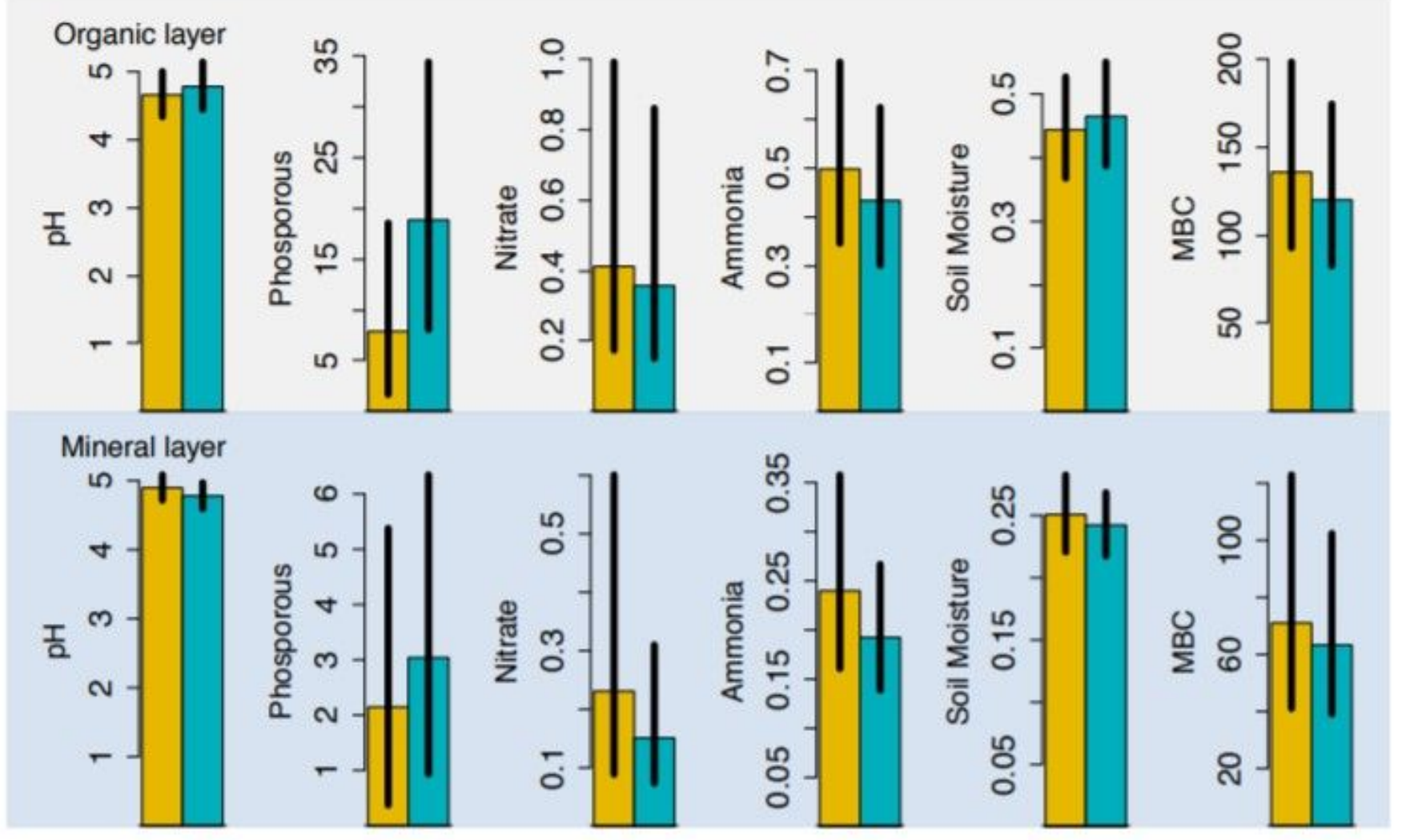

Figure 3

Soil properties in the organic (top) and mineral (bottom) layers. All soil properties were non-significant between the ambient (gold) and weeded (teal) treatments at $P=0.05$. 


\section{Organic layer}

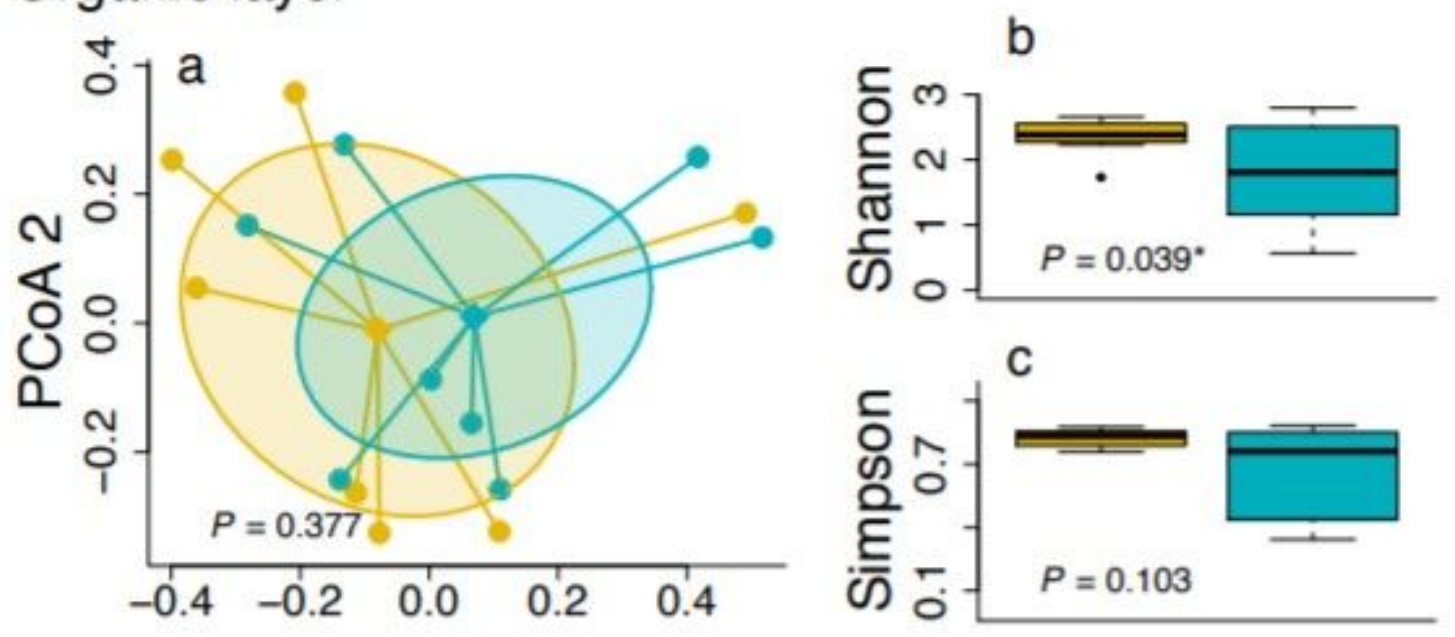

\section{Mineral layer}
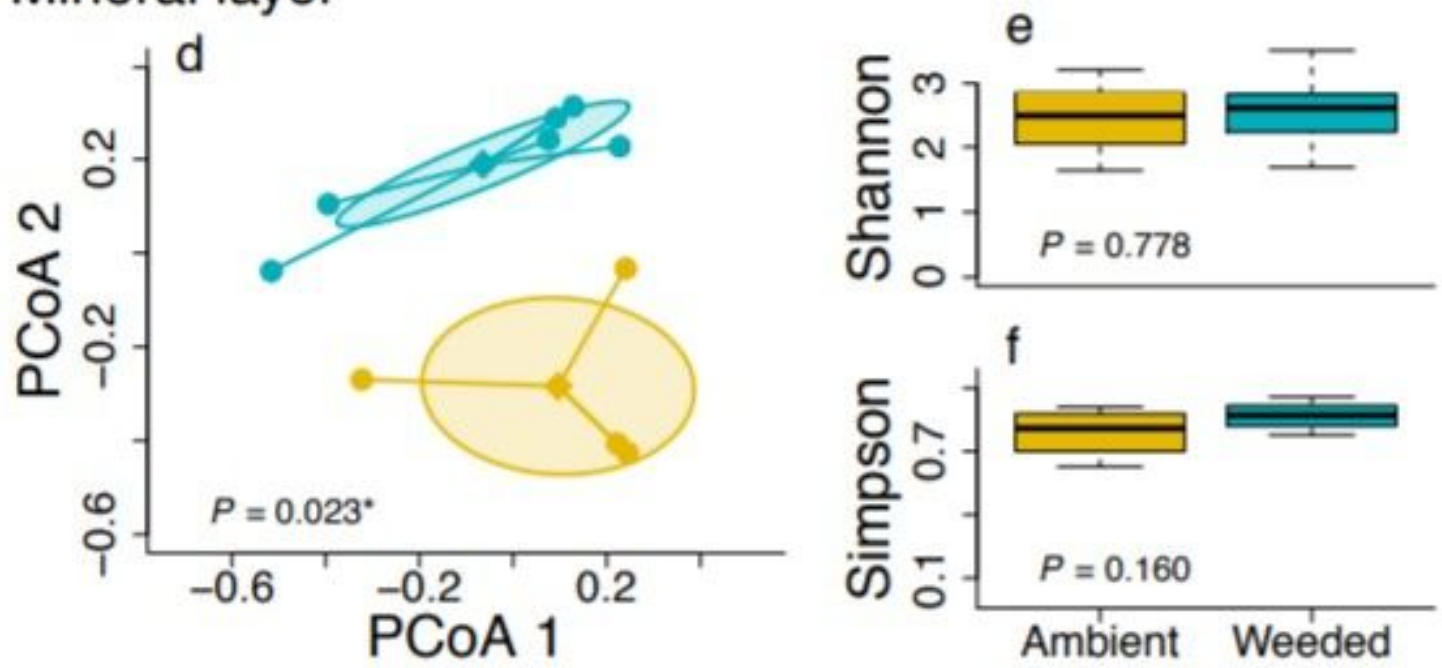

Figure 4

Comparison of Alliaria treatment effects (ambient or weeded) on soil fungal community beta $(a, d)$ and alpha diversity (b, c, e, f) for two soil layers: organic (top) and mineral (bottom). The Principal Coordinates Analysis graphs (left) illustrate the similarity or dissimilarity (beta diversity) of the soil fungal community between treatments based on species abundance. The graphs to the right show differences in soil fungal Shannon-Wiener diversity and Simpson Index between the ambient (gold) and weeded (teal) treatments. 

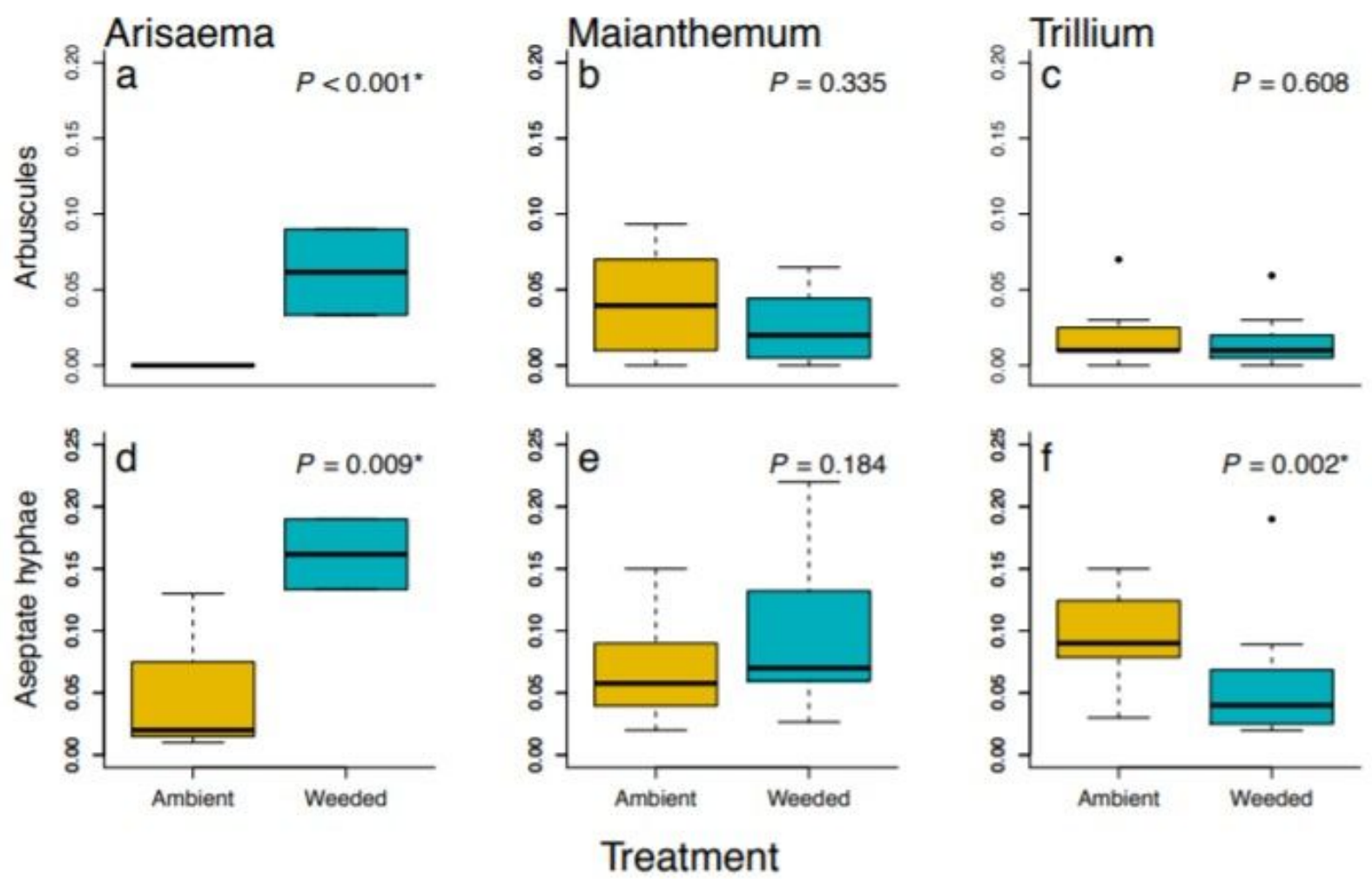

Figure 5

Root colonization of the focal native perennials (Arisaema, Maianthemum, and Trillium) in the Alliaria ambient and weeded treatments in 2018. The response variable was the proportion of arbuscules or aseptate hyphae present across 60-125 fields of view. 

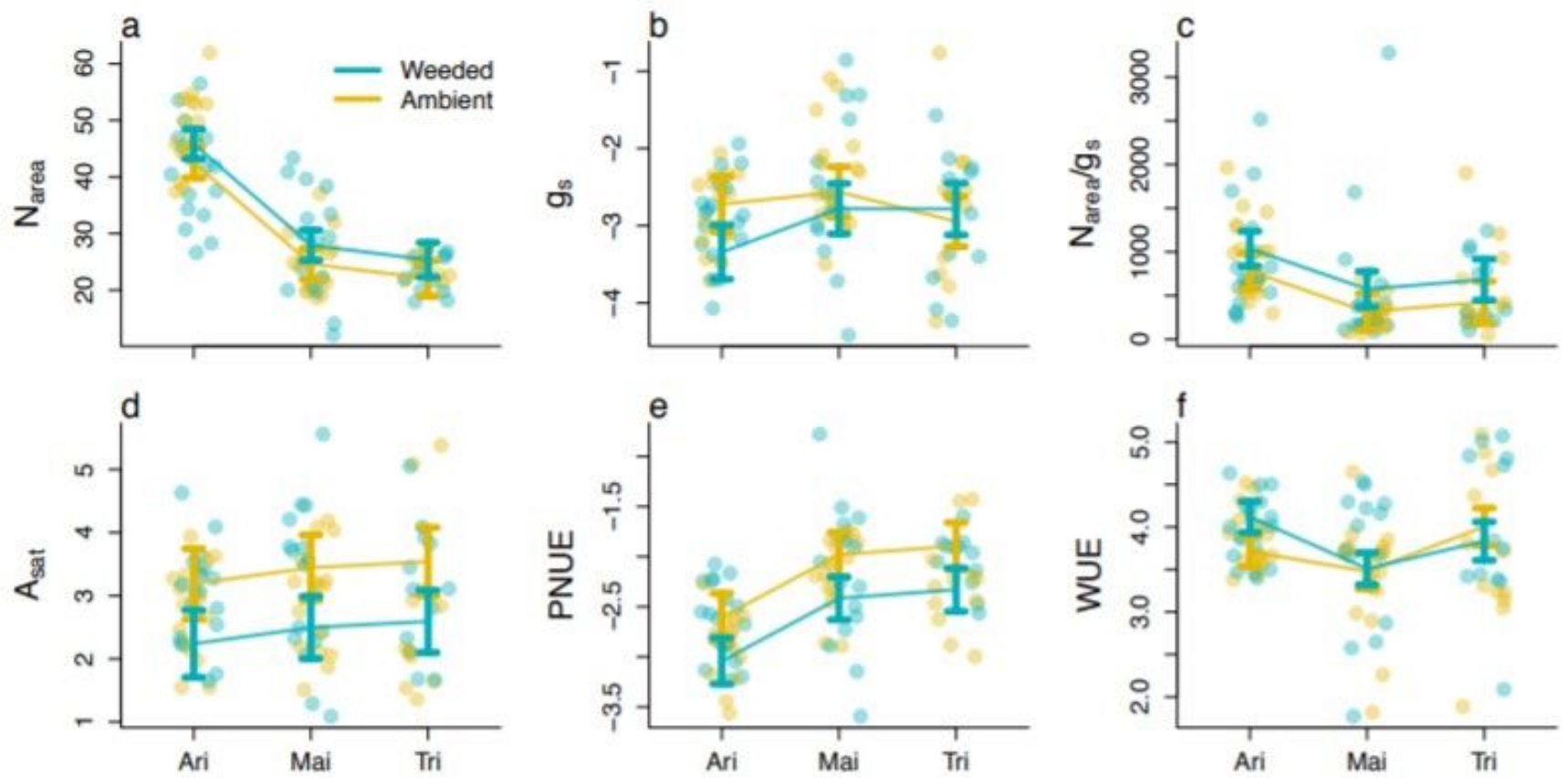

Figure 6

Physiological traits and resource use efficiencies for the non-reproductive life stage in the Alliaria weeded (teal) and ambient (gold) treatments. The interation term between the Alliaria treatment and species are significant at $\mathrm{P}=0.05$ for WUE and gs. The main effect of treatment is significant for Asat, PNUE, Narea, and Narea/gs.

\section{Supplementary Files}

This is a list of supplementary files associated with this preprint. Click to download.

- BialicMurphyetalSupplementaryanonymous.pdf 